\title{
Polilingual educational environment: the readiness of higher school teachers for the pedagogical providing of student's training
}

\author{
L.S. Znikina ${ }^{*}$, and D.V. Sedykh ${ }^{2}$ \\ ${ }^{1}$ T.F. Gorbachev Kuzbass State Technical University, Kemerovo, Russia \\ ${ }^{2}$ T.F. Gorbachev Kuzbass State Technical University, Kemerovo, Russia
}

\begin{abstract}
The article deals with the issues of actualizing the pedagogical providing of students' training in the higher school polilingual educational environment. The brief theoretical analysis of up-to-date scientific trends of organizing educational process in multicultural conditions is given. The purpose of the article is to accent and identify the readiness of higher school teachers for students'training in polilingual educational environment, to verify the deductions and ideas using the estimate procedures, pedagogical experiment and generalization of results.
\end{abstract}

\section{A problem statement}

New scientific and theoretical ideas for the professional training of specialists are implicitly related to the innovative nature of changing the social and cultural environment at the university. The modern pedagogical community is focused on the study of the problems defined recently by the obvious innovations of multicultural exchange. It is no coincidence that in the interdisciplinary consideration of educational processes the educator's readiness to work in a multilingual and multicultural educational environment can be regarded as the main factor of effective organization of educational process.

An innovative presentation of the issues of students' training in a multilingual educational environment from the standpoint of an integrative consideration of psychological, pedagogical, sociocultural, linguistic and philosophical aspects allows to reflect a comprehensive study of the problem of professional teachers' training in modern higher education [1-6].

The pedagogical dialogue as a main component of cross-cultural and multilingual communication (interaction) is considered to be one of the communicative dominant in students' training [7].

Accordingly, we are to highlight the teacher' role as a mediator of certain knowledge, individual axiological norms, social and cultural values and attitudes in a multicultural university that can sometimes be the cause of obvious methodological difficulties in teaching $[4 ; 8-10]$. A teacher should be able to analyze, interpret, predict the

*Corresponding author: ipcs-profped@yandex.ru 
communicative behavior of students as participants of foreign language communication in a multilingual environment, based on knowledge of linguistic professional means of persuasion and assessment, linguistic, cultural, ethnic, age singularities, given the specificity of national mentality of specialists [11].

It is worth emphasizing the necessity of regular, systematic improvement of the professional and individual educators' skills and abilities in modern conditions of a multicultural educational environment. Obviously, a teacher needs to reach such a level of professionalism that would be perceived by a student as a standard to strive for in order to be successful in personal professional terms. The non-stop creative search for new ideas and solutions contributes to comprehensive achievement of personal, professional and cultural development, the formation of an individual teaching style.

\subsection{The objective of the work}

To identify the features of the educational process in the multilingual educational environment, the need for methodological and intercultural readiness of the teaching staff able to work in such conditions, to provide the necessary level of students' activity, the extensive work of various methods of psychological and pedagogical diagnostics use was organized: the observations, questionnaires, individual and group discussions with students and teachers. To generalize the qualitative analysis, a set of questionnaires and diagnostic tools were used. The main goal of this study stage was to identify possible problems and optimize the current educational processes.

The research was based on the modern methodological conceptions of the pedagogical processes and theories. The analytical reflection and estimate procedures, pedagogical experiment, comparison, generalization were implemented.

\section{Materials and the results of the research}

The object of our research we formulize as following: to identify new problems associated with the organization of the educational process in a multilingual environment, to select and rationalize study methods. The higher school teachers have usually the set of the particular questions training students:

- What is the mechanism for conducting a "dialogue of cultures" in the process of multilingual and multicultural interaction?

- How to resolve ethno-cultural differences in the educational process?

- How to maintain a favorable psychological microclimate in a group of students of different nationalities?

- What factors of personal, professional and cultural development of students are especially important in organizing students' training in a multicultural educational environment?

- What kind of peculiarities need to be taken into account when organizing the educational processes for students (representatives of different nationalities and ethnic groups) and what psychological and pedagogical conditions need to be created for successful educational activities?

In order to identify the peculiarities of teaching students in the multilingual environment of the university, we offered teachers a set of certified questionnaires. We present some of the questions below:

$>$ What factors of personal and professional students' development in the multilingual educational environment are especially important? 
$>$ What kind of teacher' facilities (for example, in teaching foreign languages) can be used to organize classroom and independent students' work (in the groups of foreign students)?

$>$ Do the educators focus on the following problems:

- low level of Russian language proficiency by foreign students;

- insufficient preparation of teachers for organizing student training in groups of foreign students;

- low level of English proficiency of students;

- $\quad$ lack of teaching facilities;

- $\quad$ insufficient consideration of the individual characteristics of students;

- unfavorable psychological microclimate in the students' group?

- Is there enough knowledge about "foreign" languages and cultures for teachers working in multinational groups?

As a result of the analysis of the responds, we received the following data to identify the features of students' training in the multilingual educational environment.

The majority of teachers $(91 \%)$ note that among the most important factors of the personal, professional and cultural development of students in the organization of the learning process in the multilingual educational environment of the university, the creation of special pedagogical conditions for the realization of the creative students' potential.

According to the respondents' opinion $(86 \%)$, the creation of a more favorable psychological microclimate is obvious. The importance of a competent "pedagogical dialogue", pedagogical interaction and positive emotional culture in the group (86\%) are noted. Teachers also accent $(100 \%)$ the need to take into account the national characteristics of a particular culture, the formation of tolerance among students in the process of interaction. The ability to manage the interpersonal interaction, teaching students foreign languages, professional communication and cooperation can be considered as a priority $(69 \%)$.

Most of the teachers - respondents (82\%) use text materials in accordance with national characteristics, and audio and video facilities taking into account the students' interests, needs, their individual, linguistic and cultural peculiarities. $76 \%$ of the respondents use guidelines to develop foreign language competencies in intercultural interaction.

Most of the respondents consider the low level of Russian language proficiency by foreign students (93\%) and the low level of English proficiency to be noted by foreign language teachers $(72 \%)$ as the main problems of organizing the teaching process in the multilingual educational environment.

The research have shown that teachers of special (profiling) departments were connected to the discussion of the problems of ensuring the educational process at the university. This resulted in the following conclusions: a necessary aspect of the implementation of interdisciplinary activities of teachers and the improvement of the methodological skills of teachers is a qualitative selection of educational and methodological resources. The result of the productive activities of teachers of humanities and specialized disciplines was the development of assignments funds and methodological recommendations, criteria basis for the adaptation of educational facilities by students to create a meaningful base of educational and methodological support for training Russian and foreign students.

The need to create unified methodological complexes was recognized by almost all teachers of the humanitarian and specialized disciplines of the university (according to the results of the survey, 97\%). The level of determining the quality of the developed methodological resources and, in some cases, adjusting them became possible due to their approbation in practical classes at the university. 
In experimental work we managed to find out that the intercultural competence of an individual includes 6 main qualities:

tolerance for ambiguity in dialogue and the ability to constructively overcome this threshold in communication;

choice of behavioral strategies : the ability to adapt one's own behavior to changing requirements and situations;

communicatively adequate behavior: the ability to understand, correctly interpret and respond appropriately to the commonly accepted speech patterns, cultural and linguistic phenomena reflected in the language;

willingness to acquire new knowledge about the culture of the target language and the ability to act in accordance with the by radiation knowledge, skills and positive attitude to culture in situations of real communication with the representatives of this culture;

respect for cultural differences in communication and behavior of interlocutors: willingness to abandon the opinion about the superiority of the norms of one's own culture over the norms of foreign-language cultures;

empathy and emotional intelligence: the ability to intuitively understand what the other person is thinking and feeling in a particular situation.

The results of the questionnaires and the discussions showed the expediency of forming such students' skills as to communicate constructively with foreign partners and to conduct business negotiations correctly.

The forms of integrative activity of teachers of special disciplines with teachers of the humanities (for example, with the departments of foreign languages) are:

$>$ educational and methodological publications;

$>$ development of topics for professional communication of future specialists;

$>\quad$ career guidance activities with students (in a foreign language);

$>$ modeling and "playing" the situations of professional communication, which are typical for the future professional activity of specialists in the intercultural conditions;

$>$ research activities and scientific publications on specific topics, etc.

As a pedagogical interaction of teachers of various disciplines, centers of psychological and pedagogical support in the educational process are expedient. The purpose of such centers is to provide psychological and pedagogical conditions for the personal development of students, to create a favorable social and psychological climate in the university staff.

As areas of activity of such services we consider psychological and pedagogical education: popularization of psychological and pedagogical knowledge among the participants of the educational process. Very important is psychological and pedagogical assessment of the educational process participants: identifying the individual students' characteristics, social maturity assessment of students, the level of the tolerance relationships. To the purpose of psychological and pedagogical support centers we attribute individual consulting: training, development of the interpersonal skills and interpersonal interaction training: the creation of favorable psychological climate, development of interpersonal relationships. One of the most important goal of such centers must be mastering ethno-cultural teacher's approaches in training students: seminars and workshops on the basics of communication, tolerant interaction, style of pedagogical interaction with position of humanization of higher education.

The analysis of the research results became the basis for identifying the features of the methodological readiness of educators and organizing students' training in the multilingual environment. It was made the preliminary conclusion that these features are associated with a vivid specificity in the socio-cultural, ethnic, psychological and pedagogical contexts.

We have formulated these features in the following way. 
Modern higher education should be projected not only on the description of intercultural characteristics, but on the conditions of real relationships and interaction with representatives of other cultures and languages.

The communicative dominant of the educational process is to be "pedagogical dialogue" as a component of polilingual interaction in the conditions of a multilingual educational environment. It is advisable to consider "pedagogical dialogue" as a key factor of intercultural cooperation [7].

Below we schematically present the components of the successful educational process providing in multicultural conditions. In the table the educator's role is stressed on.

According to the logic of our research the psychological concept "attitude" is interpreted in the context of polilingual educational environment. More specifically, we refer to "ethnic attitude" based on tolerance, respect, assertive behavior to the people belonging to the "other" ethnic groups and brought up on samples and values of "other" culture. This concept is quite deeply studied in scientific works [12-14].

The concept "attitude" was originally introduced by German school (L. Lange) and developed by D. Uznadze school. It is characterized as a number of micro-processes and phenomena of a general psychological nature.

We consider an environment as a powerful social resource that forms certain personal qualities of the educational process participants, including the characteristics of inter-ethnic and cross-cultural communication.

In our research, we rely on ideas of researchers, who consider ethnic attitudes as the readiness of representatives of a particular culture to act and behave in a particular multicultural environment.

We share the conclusions that a socially conditioned attitude is the readiness and predisposition of a person to perceive any external information, including social, on the basis of an already formed own position and previously acquired experience of interpersonal communication [12-14].

The approaches of researchers to the strategy of intercultural dialogue and tolerance are valuable for our scientific work [15-18], which allow us to conclude that interethnic attitudes can be formed, to identify the mechanisms of their harmonization in the multicultural educational space. The theory of social attitudes is aimed at identifing the mechanisms for the formation of a positive intercultural dialogue, since ethnic attitudes, in fact, cannot be neutral, and depending on the "emotional saturation" are divided into positive and negative. In the context of modern higher education, the academic exchanges are important to create an educational environment that would contribute to the elimination of possible interethnic misunderstandings (sometimes aggressiveness), the formation of interethnic tolerance, which can be regarded as the basis of a constructive intercultural dialogue $[19 ; 20]$.

Taking into account the reflection and ideas of known researchers [21-23] we identified the most important areas of educational activity at higher school in conditions of intercultural contacts in students' training:

$>\quad$ involvement of Russian students in class-work with foreign students (organization of student's supervision and coordination);

$>$ expansion of the institution of supervision: coordinator of study groups working in an international audience, as well as student coordinators must have multicultural competence, which implies knowledge about the socio-cultural characteristics of students, the characteristics of foreign educational systems, the characteristics of socialization, sociodemographic, paralinguistic, non-verbal means and kinetic peculiarities of communication with representatives of other cultures, the ability to practically apply this knowledge; 
availability of modern teaching and methodological support in the educational process, recommendations for optimizing the process of teaching and education in the context of interaction between representatives of different cultures;

$>\quad$ involvement of foreign students in cultural and leisure activity ( sports clubs, Art studios, etc.);

$>$ upgrading the Russian language level: the higher language level, the more effective adaptation is;

$>$ creating conditions for foreign students to maintain their usual way of life;

$>$ organization of special psychological classes and lectures for foreign students: a foreign student should be able to receive qualified psychological help and support at the University.

Table. The methodical readiness of higher school teachers for cross-cultural interaction in student's training.

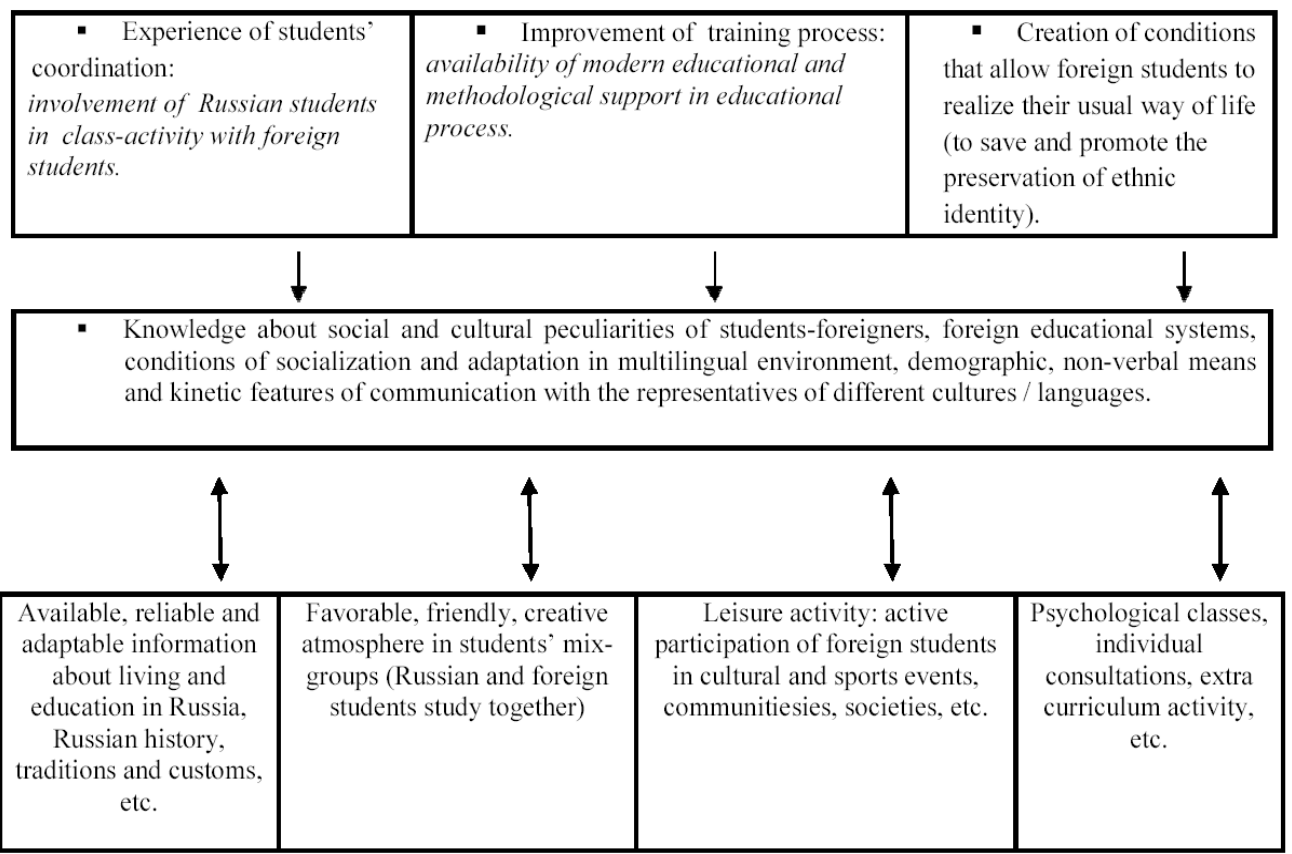

The described areas of educational activity at higher school in intercultural conditions can determine the level of teacher's professional development [7].

\section{Conclusions}

The study determines the problems of organizing the educational process in a multicultural environment. The specificity of the process of teaching students in the multilingual educational environment of the university is associated with the peculiarities of the sociocultural, interethnic, psychological and pedagogical formats. It is important to take into account the level of methodological readiness of teachers for the educational process in the multilingual and multicultural environment of the university.

We are to determine the teacher's methodological readiness for teaching students in multilingual conditions from two positions:

- teacher as a professional in a special field of knowledge; 
- teacher as a moderator of pedagogical dialogue (polylogue) in a multicultural environment.

We can conclude that pedagogical dialogue in a multilingual educational environment is a component of intercultural interaction, productive pedagogical cooperation of the educational process participants. On the one hand, this is a professionally oriented and culturally meaningful function of the teacher, on the other hand, the attitude of the student as a carrier of a specific ethno-cultural attitude to the environment, which is expressed in the level of readiness for co-creation. The important educator's function is to develop interpersonal perception, co-creation, ethical-cultural and cross-cultural interaction with the students in the educational process.

\section{References}

1. V.I. Karasik, Language of the Social Status ,p. 333(M.: GNOSIS, 2002)

2. N. Adler, International Dimentions of Organisational Behaviour, South-Western College Publishing Ohio, 275-276 (1997)

3. C. Geerts, The Interpretation of Cultures, p. 124 (New York, Basic Books, 2000)

4. I.E. Bryskina, The model of bilingual / bicultural language education at higher school. Vestnik Tambovskogo universiteta, 3 (83), 123-131 (2010)

5. H.D. Brown, Breaking the language barrier, p. 184 Yarmouth, ME: Intercultural Press (1991)

6. V.P. Bespalko, The components of the pedagogical technology, p. 192. (Moscow: Pedagogics, 1989)

7. L.S. Znikina, D.V. Sedykh, Organization of students' training of foreign-language professional communication in bilingual educational environment. (Problems of modern pedagogical education), series "Pedagogics and Psychology", 56 (3), 49-56 (2017)

8. V.V. Ignatova, Pedagogical factors of spiritual and creative personality foundation in educational process, p. 365 (Krasnoyarsk, 2000)

9. K.A. Abdulhanova-Slavskaya, Activity and consciousness of a personality as a subject of activity. Psychology of personality in sociological society. Activity and personal development, p. 183 (Moscow: Science, 1989)

10. A.M. Akopyanc, Communicativ and pragmatic aspects of training process at higher school Universitetskie chteniya, Part III (6-13, Moscow Pedagogics: PGLU (2009)

11. D. Fransis Woodcock, The unblocked manager. A practical guide to self development, p. 320 (1991)

12. N.M. Lebedeva, Social psychology of ethnic migration, p. 195 (Moscow, 1993)

13. B.F. Lomov, Methodological and theoretical problems of psychology, p. 444 (Moscow: Science, 1984)

14. R.D. Lambert, Education Exchange and Global Competence, p. 231 (New-York, Council on Educational Exchange, 1996)

15. A.I. Timonin, Conceptual background of social and pedagogical providing of students' professional foundation at the University, p. 216 (Kostroma, 2007)

16. V.I. Slobodchikov, Educational environment: realization of educational purposes in the cultural space. New values of education, 7, 177-184 (1997)

17. V.V. Serikov, Personality approach in education: the concept and technologies, p. 152 (Volgograd, 1994) 
18. R. Irwing, Culture shock: negotiating feelings in the field. Anthropology Matters Journal, 9 (1), 11 (1997)

19. M.V. Klarin, The technology of education: ideal and reality, p. 180 (Riga: Experiment, 1999)

20. K. Parry, Culture, literacy and learning English, p. 270 (Porsmouth, NH. Boghton / Cook, 1998)

21. M.B. Krylova, Culture of education. The Cultural factor, p. 272 (Moscow: National Education, 2000)

22. J.D. Mayer, C.D. Cobb, Educational policy on emotional intelligence: does it make sense? Educational psychological review, 12 (2), 163-183 (2000)

23. D. Hymes, Gumperz J., Models of the Interaction of Language and Social Life Directions in Social linguistics: the Ethnography of Communication, 35-71 (New York, 1972) 